\title{
Optimization of Multimedia English Teaching in Context Creation
}

\author{
Weiyan Yang \\ Foreign Language Department \\ Shantou Radio \& TV University \\ Dongxia North Road, Shantou, Guangdong, P.R. China, 515041 \\ E-mail: auntynn@163.com \\ Fan Fang \\ English Language Center \\ Shantou University \\ 243 Daxue Road, Shantou, Guangdong, P.R. China, 515063 \\ E-mail: ffang@stu.edu.cn
}

This paper is a stepwise result of the Educational and Scientific Project of the Eleventh Five-Year Plan of Shantou, 2008. The subject title of our search is "The Reform of the College English Curriculum and the Harmonious Interaction of Teachers' Professional Development" (Project No. 08JKSY032).

\begin{abstract}
Using multimedia to create a context to teach English has its unique advantages. This paper explores the characteristics of multimedia and integrates how to use multimedia to optimize the context of English teaching as its purpose. In this paper, eight principles, specifically Systematization, Authenticity, Appropriateness, Interactivity, Coordination, Pluralism, Intelligibility, and Penetrability, are summarized to fulfill this purpose. Through using multimedia and the creation of context in optimizing English language teaching, the study also hopes to improve students' competence in thinking and practicing, which can be adopted to provide an effective method of using multimedia in English teaching and learning.
\end{abstract}

Keywords: Multimedia English Teaching and Learning, Context Creation; Principle, Optimization

\section{Introduction}

With the spread and development of English around the world, English has been learned and used by more and more speakers. Taught as a foreign language, English also enjoys high prestige in China. The use of the English language in China has increased rapidly in recent years, particularly in response to the 2008 Olympic Games and joining the WTO. Adamson (2004: 195) points out the importance of English in China:

At present, the role and status of English in China is higher than ever in history as evidenced by its position as a key subject in the curriculum, with its growing use as a medium of instruction as many schools adopt a bilingual approach to education; and as a crucial determinant for university entrance and procuring well-paid jobs in the commercial sector.

Since there are more and more English learners in China today, different teaching methods have been implemented to test the effectiveness of the teaching process. One method involves using multimedia in English Language Teaching (ELT) in order to create English contexts. This helps students to get involved and learn according to their interests; it has been tested effectively and is now widely accepted for teaching English in the modern world.

The concept of "Context" was first proposed by Malinowski (1923). He distinguished two types of context: "Situational Context" and "Cultural Context". Context can also refer to the environment of using the language, while broader context refers to the specific environment of language (meaning both specific occasions and the social environment). 
Narrowly, context denotes the specific context of the language forms, also known as the scenario (see also, for example, Davies, 2005: 28).

Halliday and Hasan (1989) think that situational context can be composed of three parts: "Scene", "Manner" and "Communication". It is true that as a social and cultural phenomenon, language is used to communicate both socially and culturally. Kramsch (1998: 6-8) points out:

Common attitudes, beliefs, and values are reflected in the way members of the group use language - for example, what they choose to say or not to say and how they say it. [...] Language is not a culture-free code, distinct from the way people think and behave, but, rather, it plays a major role in the perpetuation of culture, particularly in its printed form.

English learners must rely on a certain language environment to achieve the goal of communication when they are learning the language. We can make use of multimedia technology, combined with teaching scenarios for the creation of a suitable context in learning English. This creates an English communicative environment and provides as many opportunities to practice language as possible to enhance students' interest in learning English. It is the primary task for English educators to train students in Communicative Competence (see, for example, Hymes, 1972) and optimize the effectiveness of ELT.

\section{Advantages of Using Multimedia English Teaching for Context Creation}

\subsection{The Status Quo of Multimedia Teaching in China}

With the rapid development of science and technology today, as well as the theme of globalization and economic integration, multimedia teaching has gradually entered the day-to-day classroom and has been especially well-promoted and popular in Chinese universities. It is known that the term "multimedia" was coined as a result of technological development; it is the combined form of words "multiple" and "media", while its counterpart is "monomedia".

There may be different definitions in terms of "multimedia", but it basically includes using such elements development as multimedia wall charts, slide projector, video, television, networks, PowerPoint, Email, Bulletin Board System (BBS) forums, language laboratories, libraries and multimedia reading rooms. Generally speaking, the core of multimedia teaching is using the computer, based on the current information, to create a platform of exchanges and communication between teachers and students through sound and text. In this way, teaching effectiveness and quality can be improved based on specific and three-dimensional teaching.

However, we cannot deny that China's multimedia teaching at the current stage is far from being prevalent everywhere. In colleges and universities among economically developed regions, multimedia teaching is still mainly in the second stage of its development. Moreover, multimedia teaching is also difficult to implement on a large-scale basis, and to develop in all locations. It is generally acknowledged that multimedia teaching, particularly using multimedia for ELT, is helpful in context creation, as well as in eliciting motivation from the students for the purpose of changing the traditional "cramming" teaching method, which may lead to so-called "Dumb English" or "Deaf English" (Note 1).

\subsection{Advantages of Using Multimedia in ELT}

Given the issue mentioned above, a question may be easily raised concerning the unique advantages of using multimedia to create a context for ELT.

First of all, multimedia teaching stresses the role of students, and enhances the importance of "interaction" between teachers and students. A major feature of multimedia teaching is to train and improve students' ability to listen and speak, and to develop their communicative competence. During this process, the teacher's role as a facilitator is particularly prominent. Using multimedia in context creation creates a good platform for the exchange between teachers and students, while at the same time providing a language environment that improves on the traditional classroom teaching model. In this way, teachers in the classroom no longer blindly input information and force students to receive it in a passive way. Instead, the English context from multimedia creation enables students to participate actively during the process. Therefore, in this context, English teaching methods gradually diversify and bring students' enthusiasm into full play with guidance from teachers. It is evident that using multimedia for context creation in ELT improves teaching efficiency and quality.

Second, multimedia teaching creates a context for language teaching. This method makes the class lively and interesting, as well as optimizing the organization of the class. Multimedia has its own features such as visibility and liveliness. During the process of multimedia English teaching, sounds and pictures can be set together, which enhances the initiative of both teachers and students. When using multimedia software, teachers can use pictures and images to enrich the content of classes, and also imagine different contexts in the process of producing teaching courseware. Students in the class can use multimedia to understand the class in a clear way. Through the whole interactive process, it is apparent that using multimedia in ELT is effective in nurturing students' interest in learning English, as well as enhancing teachers' interest in English teaching. As Zhang (2006: 111) points out:

Through multimedia and network technology we can offer students not only rich sources of authentic learning materials, 
but also an attractive and a friendly interface, vivid pictures and pleasant sounds, which to a large extent overcomes the lack of authentic language environment and arouses students' interest in learning English.

In addition, multimedia teaching is also flexible. It is obvious that the context can be created not only in the classroom, but also after class. Multimedia language teaching can also create a multimedia language environment for the purpose of conducting language teaching. English teaching itself must focus on the guidance of teachers and be student-centered (see, for example, Holec, 1981), which we believe is one of the principles for language teaching. Students are bound to have some problems in classroom teaching, which can be addressed under the guidance of teachers. In such circumstances, students can use the new technology to their advantage, such as manipulating the network to contact teachers, and receiving answers by email.

Through this method of language teaching, teachers can also bring in cultural content and other topics in English teaching, such as education in Britain and the United States, as well as Western festivals and customs. Multimedia language teaching can be used to help students to study under "collaborative learning" (Note 2). Through the production of courseware such as PowerPoint, students receive the teachers' guidance and learn to cooperate with each other. As Zhang (2006: 112) also points out: "Multimedia and network-based language teaching provides students with learning flexibility as far as learning materials, learning time, learning place and learning pace are concerned".

\section{The Principles of Optimizing Multimedia English Teaching on Creation of Context}

English teaching scenarios require teachers to engage in classroom teaching according to the real world. The main materials, rich emotional scenes and the specific atmosphere, inspire and attract students to take the initiative to study. As a result, they ensure the effectiveness of the multimedia context creation in English teaching. Multimedia technology is a remedial teaching method in addition to the traditional teaching process. The focus of ELT is still on students' class activity; therefore, the design of multimedia courseware materials should be close to the content, identifying the entry point of the contents, and following students' thought. In order to fulfill these goals, we identify eight principles to be noted in the process of optimizing multimedia English teaching in context creation, using different forms and methods to design all kinds of practical contexts for language students. We believe that these principles will fully embody the advantages of multimedia English teaching in achieving satisfactory results.

\subsection{The Principle of Systematization}

Based on the linguistic theory of systematic functions of Halliday and Hasan (1989), the purpose of English teaching is the development of students' Meaning Potential, which uses the cultural significance of the target language to raise the English communicative competence. Students not only learn the vocabulary, grammar, and text systems, but also the principles of cross-cultural communication and practices of special meaning systems, behavior, and choices in the language according to the context. The aim of English teaching is to provide students with such a learning environment and conditions. Multimedia and network teaching also provide a more advantageous condition for the development of Meaning Potential to students. For example, when we set the English curriculum for multimedia English teaching, we should consider the establishment of different systems of language teaching for the target language and then divide the learning process into different phases. Through the background and introduction processes, students improve their Meaning Potential in the various language networks in the project through learning and memorizing; through the construction learning process, students put these projects in the appropriate places in the system, from which the students learn the project by heart; through the choice learning process, students learn to choose their own language according to their needs, composing the communicative structure for the language environment, and grasping the Meaning Potential of the language.

\subsection{The Principle of Authenticity}

The real context can meet students' practical needs in communication. During the process of implementing context into language teaching, students will gain a profound feeling for language learning; we believe that it is a convenient and effective measure to provide real context through a multimedia network. In ELT, teachers have various choices of multimedia software, videos, films, slides, photographs, and other media. They can also use multimedia tools to provide vivid materials, creating real contexts and giving background information in order to help students to create an atmosphere of participation and exchange in different contexts. This method of context creation brings students into the real situation of communication and provides Context, Correlation, Embedded Text, Synchronic Text, Super Text, and other Inter-text Contexts (see, for example, Henige \& Zamora, 1989) to make it a benefit for changing knowledge into practical skill.

\subsection{The Principle of Appropriateness}

Multimedia and networks are characterized by the prolific development of information. Although students can access massive amounts of information, they cannot digest and absorb it directly. Therefore, they cannot develop their long-term memory and communicative competence. In order to optimize multimedia English teaching in context creation in terms of the appropriate selection of information, we should take care to classify and organize information 
effectively and make choices according to students' needs. Otherwise, there will be too much information for them. Moreover, attention should also be paid to fit students' different requests when designing the curriculum, following the process of information exchange. For example, when setting the curriculum, it should be known that the difficulty should be slightly higher than the students' actual level. It is true that appropriate control of the type and amount of material, as well as making good use of time, can be more effective when learning English through multimedia language teaching.

\subsection{The Principle of Interactivity}

During the process of in-classroom English multimedia teaching, it is believed that the goal of interaction between teachers and students is to achieve exchanges in the real language context. Teaching content should be designed with consideration of how to achieve interaction between teachers and students, among students themselves, and between students and modern technology (see, for example, Brown, 2001). Through these different types of interaction, personalized learning, collaborative learning (see, for example, Beckman, 1990), and other modes of learning can be combined in order to help students to take the initiative. Through this process, students can discover ideas and methods, and learn how to solve problems by themselves. This method of language teaching provides various ways to promote the growth of students' creativity, cooperation, and interaction. It also makes multimedia language teaching and learning active and vivid, from which we can see that the interactive exchange of information reflects the characteristics and advantages of multimedia teaching in context creation.

\subsection{The Principle of Coordination}

During the process of optimizing multimedia English teaching in context creation, it is inappropriate to change the classroom into a platform for information exchange between students and modern machinery. Multimedia language teaching is not simply a "means of introducing multimedia" (see, for example, Gong \& Zhou, 2007). Attention should be paid to coordination between teachers and students, teaching materials and methods, theory and practice and multimedia teaching and the real learning environment. Students learn to take the initiative to promote exchanges with teachers, and vice versa; it is not appropriate to apply too many teaching methods or provide too much courseware to students. It is important to choose the most suitable teaching method for creating a real teaching and learning environment to help students gain the most intuitive and cultural information using various functions and forms of multimedia presentation. In this way, students can develop self-confidence in communication and improve their overall English skills.

\subsection{The Principle of Pluralism}

Pluralism with Intelligence requires teachers to choose and create appropriate and comprehensive educational methods to promote the full development of students based on the educational content, their intelligence structure, their interests, and their different characteristics. Teaching English in order to create a multimedia classroom context not only restricts but also affects the students' own intellectual development. English teachers should constantly make use of the advantages of multimedia teaching to update English teaching concepts and teaching strategies, and produce scenario-style, animation-style, case-style, analogue-style, and game-show-style films as self-supporting material to inspire students. This will create multimedia English teaching context conducive to the development of Multiple Intelligence (Gardner, 1983) (Note 3), as well as diversifying the teaching forms, to fully motivate students to capture and understand the information, and encourage them to learn English. We believe that this is an effective way of promoting students' all-round development of intellectual awareness, and to maximize their potential for intellectual development.

\subsection{The Principle of Intelligibility}

The process of understanding discourse is the process of the context establishment. An effective way to understand the discourse is to choose and establish an appropriate context to get people involved in the context. This includes communicative context, communicative environment, and communication based on common sense. English teachers should socialize and contextualize the multimedia classroom, as well as trying to transplant the real use of English into an in-classroom multimedia environment to improve students' interpretative skills. It is helpful for teachers to use the characteristics of contexts in teaching materials to enable students to learn when and where they should speak English in line with the discourse and ultimately improve their English language skills. Teachers can also use multimedia to help students to predict the text in order to grasp the context and enhance their comprehensive skills. From a practical context to language understanding and usage based on different types of training, students may improve their communicative competence effectively in different contexts.

\subsection{The Principle of Penetrability}

To achieve the success of multimedia English teaching in context creation, English teachers should involve their own sincere feelings in the classroom and make use of multimedia to stimulate students' emotions. This is a joint method, where the two elements complement each other to promote and optimize the context creation of multimedia English 
teaching, which is one of the internal driving forces of students' learning interest. The learning process can stimulate students' desire to learn, so that students leave with positive feelings after class. English teachers should also learn to explore aesthetic factors in the context creation in multimedia language teaching, and make use of the "display" functions of multimedia to make timely demonstrations to help students learn about the aesthetic capacity of English, so that they are able to express their personalities in the foreign language.

\section{Optimization of Multimedia English Teaching to Achieve Context Creation}

The MIT Open Course Ware (OCW) (http://ocw.mit.edu/) of America and the National Program of Web-Delivery for Elaborate Course (NPWDEC) of China can be used as examples of this process; both of these projects are based on the integration of the Internet and multimedia Information Technology (IT), and are also open and sharable projects with wide influence. The NPWDEC integrates texts, pictures, videos, and students' self-evaluation. Through sharing information and course resources on the Internet, some basic public required courses such as "computer" and "College English" have brought about teaching reform and course construction, as well as optimizing the context of the multimedia teaching of English.

Currently, software such as PowerPoint, Authorware, Flash, Director, and Founder Author Tool can all be used to make multimedia courseware. We believe that it is quite important for English teachers to learn, master, and create interactive courseware to optimize the context creation of ELT. It is also important that English teachers fulfill the aim of multimedia English teaching for the purpose of context creation through meeting certain requirements such as Intuition with Association, Inference with Summary, and Cooperation with Interaction, as well as being aware of the relationships between them.

\subsection{The Creation of Intuition with Association}

This method of context creation aims to use multimedia skill to record reality, and to present a story or topic background to students in terms of their teaching need. In this process, students are provided audio-visual materials, English newspapers, journals and movies, through which they can learn how to relate these materials to the knowledge they learn; this will impel them to develop their imagination and creative thinking. We believe that through this method of language teaching, students can enlarge their horizon of knowledge as well as constructing a system of knowledge concerning language.

For example, when talking about "Earthquakes", teachers can find videos, pictures, texts, news, and reports concerning the topic and create courseware in the teaching process. During the process, students come to understand the consequences of an earthquake, as well as learning related vocabulary and phrases such as aftershock, disaster relief supplies, Quake Lake, mountain landslide, life detection instrument and hydroelectric plant. Students can also write an essay to summarize what they have learned after learning the topic. In this way, students not only understand the text more effectively, build up a vocabulary and enhance their understanding of the life value, but also relate the learning process with the real world. In this way, students participate in language learning directly and improve both the input and output of the information.

\subsection{The Creation of Inference and Summary}

This method aims to use multimedia technology to create a particular situation. During this process, various situations and examples with which students are familiar can be created, as well as relating these to students' experiences and helping them observe and summarize the general rules of language learning. This method of context creation has the advantage of helping students to construct more knowledge, and to improve their memory and inference ability. For example, when talking about the preposition "against", teachers can find examples of the usage of this word in an online dictionary such as JuKuu (http://www.jukuu.com/) and provide different contexts with specific meanings of this word:

a. Five members voted for the proposal, eight voted against, and two abstained.

b. A group of men were charged (with) conspiring against the duly elected government.

c. They accused him of having a prejudice against his women employees.

d. We make copies of our computer disks as a safeguard against accidents.

e. He had the idea of shooting them against a completely plain white background.

f. The tide of public opinion seems to be turning against the government.

In this way, we hope that different meanings of the word "against" in different contexts can be learned effectively by students.

\subsection{The Creation of Cooperation with Interaction}

This process is a method using online communicating tools such as BBS, ICQ or email to create a learning platform. An interactive multimedia language laboratory can also be used to create a cooperative and communicating environment for 
teachers and students. The creation of multimedia English teaching breaks the limitations of time and space of ELT. Therefore, context creation is not limited to class time. In this way, students have more opportunities to "get in touch with" English, while teachers can also understand students' needs in language learning and communicate with them in a timely fashion.

For example, when talking about the topic of "Environmental Protection", teachers can ask students to have group discussions about the general background of the topic. After class, teachers can also find background information of this topic, and use these methods of communication (BBS or email) to contact students and give them the names of different kinds of pollution, such as Water Pollution, Air Pollution, White Pollution, Acid Rain, and Red Tide. Courseware can also be used for discussing the solutions to these environmental problems. Teachers can tell the students: "Write down as many general environmental problems as you can think of. Then, think of solutions to one of the problems you have come up with". Internet resources can also be used to create an interactive context during this process. Using this method, we hope that students' positive outlook concerning language learning can be enhanced. This is a rapid and economical teaching method.

However, this method of context creation requires interaction and communication between teachers and students. If one party is lacking, the coordination and context creation is difficult to implement. Therefore, we believe that in the current situation, the spread and achievement of using multimedia English teaching in context creation should be carried out step by step.

\section{Conclusion}

"Ideally, the purpose of both the traditional and computer-assisted cooperative language learning classrooms is to provide a space in which the facilitation of learning, and learning itself, can take place" (Shi, 2008: 76). It is true that one of the ultimate goals of multimedia language teaching is to promote students' motivation and learning interest, which can be a practical way to get them involved in the language learning. Context creation of ELT should be flexible to fit the students' needs. Moreover, a good multimedia English teaching context should be based on the openness and accessibility of the teaching materials and information. During the process of optimizing the multimedia English teaching, students are not too dependent on their mother tongue, but will be motivated and guided to communicate with each other.

Concerning the development of technology, we believe that in future, the use of multimedia English teaching will be further developed and combined with the use of the Internet (this method of language learning has been applied in some universities in China, such as Beijing Foreign Studies University, Fudan University, Nanjing University, and Shantou University). The process of English learning will be more student-centered but less time-consuming. Therefore, it promises that the teaching quality will be improved and students' applied English skills can be effectively cultivated, meaning that students' communicative competence will be further developed.

It is also important that using multimedia English Teaching can be an appropriate method to help students to "get a sense of the sociocultural context in which the language is used" (Kramsch, 1999: 31), as well as raising students' language awareness under the framework of World Englishes (see, for example, McKay, 2002, Kunschak, 2004). In conclusion, we believe that this process can fully improve students' ideation and practical language skills, which is helpful and useful to ensure and fulfill an effective result of teaching and learning.

\section{References}

Adamson, B. (2004). China's English: A History of English in Chinese Education. Hong Kong: Hong Kong University Press.

Beckman, M. (1990). Collaborative Learning: Preparation for the Workplace and Democracy. College Teaching, 38(4), pp. 128-133.

Brown, H. D. (2001). Teaching by Principles: An Interactive Approach to Language Pedagogy. Beijing: Foreign Language Teaching and Research Press.

Davies, A. (2005). A Glossary of Applied Linguistics. Edinburgh: Edinburgh University Press.

Gardner, H. (1983). Frames of Mind: The Theory of Multiple Intelligences. New York: Basic Books.

Gong, W., \& Zhang, W. (2007). Thinking on the Application of Multimedia into College English Teaching. US-China Foreign Language, 43 (5), pp. 36-38.

Halliday, M.A.K., \& Hasan, R. (1989). Language, Context, and Text: Aspect of Language in a Social-semiotic Perspective. Oxford: Oxford University Press.

Henige, D., \& Zamora, M. (1989). Text, Context, Intertext. The Americas, 46 (1), pp. 17-40.

Holec, H. (1981). Autonomy and Foreign Language Learning. Oxford: Pergamon. 
Hymes, D. (1972). On Communicative Competence. In: Pride, J. B., \& Holmes, J. (eds.) Sociolinguistics. Penguin: Harmondsworth, pp. 269-293.

Kramsch, C. (1998). Language and Culture. Oxford: Oxford University Press.

Kramsch, C. (1999). Teaching Text and Context through Multimedia. Language Learning \& Technology 2 (2), pp. 31-41.

Kunschak, C. (2004). Language Variation in Foreign Language Teaching: On the Road to Communicative Competence. Frankfurt/Main: Peter Lang Publishing.

Malinowski, B. (1923). The Problem of Meaning in Primitive Languages. In: Ogden, C. K. \& Richards, I. A. (eds.) The Meaning of Meaning: A Study of the Influence of Language upon Thought and the Science of Symbolism. London: Routledge \& Kegan Paul Ltd., pp. 451-510.

McKay, S. L. (2002). Teaching English as an International Language: Rethinking Goals and Approaches. Oxford: Oxford University Press.

MIT Open Course Ware. <http://ocw.mit.edu/>. [accessed August 2008].

Richards, J. C., Platt, J. \& Platt, H. (1992). Longman Dictionary of Language Teaching \& Applied Linguistics. (English-Chinese Edition. Reprinted, 2000). Beijing: Foreign Language Teaching and Research Press.

Shi, L.H. (2008). Study of Metacognitive Strategies in Computer-assisted Cooperative Learning Environment. Teaching English in China, 31 (1), pp. 69-79.

Zhang, F. (2006). Using Multimedia and Network Technology to Reform CET in the Teaching of New Horizon College English. Teaching English in China, 29 (3), pp. 111-114.

\section{Notes}

Note 1. "Dumb English" or "Deaf English" can both refers to "a consequence that students cannot use English to communicate with others".

Note 2. Cooperative Learning is "an approach to teaching and learning in which classrooms are organized so that students work together in small co-operative teams. Such an approach to learning is said to increase students' learning since a) it is less threatening for many students, b) it increases the amount of student participation in the classroom, c) it reduces the need for competitiveness, and d) it reduces the teacher's dominance in the classroom" (Longman Dictionary of Language Teaching \& Applied Linguistics).

Note 3. According to Gardner, the eight core intelligences include: Linguistic Intelligence, Logical-mathematical Intelligence, Spatial Intelligence, Bodily-kinesthetic Intelligence, Musical Intelligence, Interpersonal Intelligence, Intrapersonal Intelligence, and Naturalistic Intelligence. 